\title{
MANIFESTAÇÕES PATOLÓGICAS ENCONTRADAS USUALMENTE EM PISOS DE CONCRETO
}

\author{
ROSANELLI, TATIANE \\ Engenheira Civil \\ Universidade do Vale do Itajaí \\ Santa Catarina; Brasil \\ tatianerosanelli@hotmail.com \\ VENÂNCIO, CAROLINE \\ Engenheira Civil phD \\ Universidade do Vale do Itajaí \\ Santa Catarina; Brasil \\ caroline.venancio@univali.br
}

\author{
VEIGA, TAIANA PAULA \\ Estudante de Engneharia Civil \\ Universidade do Vale do Itajaí \\ Santa Catarina; Brasil \\ tpaulaveiga@gmail.com
}

\section{RESUMO}

O presente trabalho objetiva avaliar as principais manifestações patológicas encontradas em pisos de concreto, por meio de pesquisas bibliográficas e um levantamento fotográfico em dez edificações, localizadas em PR, SC e RS. Os pisos de concreto foram analisados em edificações com 5 anos de idade até 30 anos. Assim, as manifestações incidentes nos pisos foram avaliadas, bem como, materiais constituintes e métodos de execução. Tais métodos foram comparados a um modelo de referência adotado, sendo ele a recuperação de um piso de garagem. As maiores falhas ocorreram nas fases de execução e projeto. Esta avaliação torna-se relevante para um posterior plano de ação, objetivando a execução de pisos com menor incidência de problemas, haja visto que os pisos são elementos que também transmitem e resistem aos esforços na estrutura.

Palavras-chave: pisos de concreto, desempenho, manifestações patológicas.

\section{ABSTRACT}

The present work aims to evaluate the main pathological manifestations found in concrete floors, through bibliographic research and a photographic survey in ten buildings, located in PR, SC and RS. The concrete floors were analyzed in buildings with 5 years old up 30 years old. Thus, the incident manifestations on the floors were evaluated, as well as, constituent materials and execution methods. These methods were compared to an adopted reference model, which is the recovery of a garage floor. The most aggravanting failures occurred in the execution and project phases. This evaluation becomes relevant for a later ation plan, aiming at the execution of the floors are elements that also transmit and resist the efforts in the structure.

Keywords: abstract, recommendations, standardization.

\section{INTRODUÇÃO}

Um piso pode ser definido como o elemento estrutural que possui a finalidade de resistir e distribuir os esforços provenientes dos carregamentos, seja pelo uso ou peso próprio, para o subleito. Estes elementos são introduzidos em ambientes onde a ação de manifestações patológicas é mais suscetível. Em garagens, por exemplo, a emissão de gás carbônico, influencia diretamente na durabilidade e na qualidade dos pisos. Além do grau de agressividade em que o piso se encontra, a execução correta é primordial e deve ser realizada por equipe devidamente qualificada e treinada (ANAPRE, 2009).

O concreto, além de atender com excelência às necessidades descritas acima, é um material de fácil manuseio e aplicação, custo reduzido quando comparado a outros materiais de mesma função, facilidade na limpeza, entre outros. Porém, devese manter o máximo controle e planejamento possível, pois mesmo que se utilizem materiais de boa qualidade, sendo mal executado, o desempenho poderá ser comprometido (CAMARGO, 2010). 
O efeito de carregamento projetado para os pisos também requerem cuidadosa atenção por parte dos projetistas no que tange a tal efeito sobre o caminhar dos usuários, pois como observou (MELLO et al, 2007), ao estudar um piso misto, com a vibração apresentada pelo mesmo a frequência do caminhar humano sofre variações, atingindo valores que ultrapassam limites normativos e afetam no conforto dos usuários que transitam sobre o local.

A baixa qualidade na fase de projeto e execução, além de ausência de manutenção ou a mesma realizada de forma incorreta, acarretam na diminuição da vida útil do pavimento, essa diminuição da qualidade do piso também acarreta no aparecimento de manifestações patológicas, afetando diretamente a parte estética e o desempenho do pavimento, o que resulta em maiores gastos para a reparação.

\section{Justificativa}

Em estudo de caso com monitoramento de execução de piso de concreto sobre laje (MÜLLER, 2014), houve a ausência de projeto e controle de qualidade do concreto executado, constatando que apesar de se seguirem recomendações normativas em grande parte do processo, a falta de etapas de execução necessárias, como a escolha de armaduras diferentes do indicado, ausência de aplicação de juntas de dilatação, adensamento e cura do concreto, apresentam problemas futuros à edificação e consequentemente aos seus usuários. Ao analisar pisos de garagem de quatro pavimentos de um edifício, o mesmo constatou que a maioria das manifestações patológicas presentes foi decorrente de falhas de execução em conjunto com a ausência de um projeto próprio para pisos de concreto.

$\mathrm{O}$ incremento de materiais não convencionais à mistura de concreto é de responsabilidade do profissional engenheiro e quando aplicado para a execução de pisos de concreto em pavimento de edificações, como garagens, pode resultar em prolongamento da vida útil do piso com consequente redução da incidência de manifestações patológicas e tempo para necessidade de se executar reparos. Tal como um estudo comprovou que ao comparar um concreto convencional com um concreto reforçado com fibras de aço e polipropileno, constatando que o último apresentou melhor desempenho para resistência à compressão e à tração (LUNA et al, 2014).

A Associação Nacional de Pisos e Revestimentos de Alto Desempenho (ANAPRE, 2009) cita o crescente aumento no número de pisos executados de forma incorreta, a partir disso, considera-se que a falta de bibliografias direcionadas especificamente aos pisos e suas manifestações patológicas mais recorrentes, seja o grande fator agravante destes problemas, tendo em vista que grande parte dos estudos existentes trata somente de outros elementos estruturais, apesar do grande uso de pisos em concreto. Desse modo, o presente artigo objetiva a execução de pisos com menor incidência de manifestações patológicas, ao estudar as manifestações patológicas em pisos de dez edificações e avaliar seus materiais constituintes, assim como os métodos de execução e manutenção, tendo como referência a recuperação de um piso de garagem.

\section{MATERIAIS E MÉTODOS}

Para estudo e determinação de parâmetros, foram utilizadas como amostra dez edificações localizadas em Balneário Camboriú - SC, Itajaí - SC, Curitiba -PR e Passo Fundo -RS, a fim de visualizar as manifestações patológicas estudadas e acompanhar a execução de recuperação. Sendo primeiramente analisada separadamente e depois a incidência das manifestações como um todo, não havendo coleta de dados de execução, como a resistência do concreto, presença de barras de transferência e outras informações de projeto, a fim de quantificar e analisar quais as manifestações mais recorrentes em pisos de concreto. Na Tabela 1 são fornecidos os dados de local, idade, tipo de tráfego e ambiente de uso de cada uma das dez edificações estudadas, sendo que para as edificações 2,6 e 10 não foram obtidas informações quanto à idade.

O trabalho em campo iniciou com o acompanhamento de execução da reparação de um piso, para constatar quais os erros na execução, em seguida foram visitadas as dez edificações, para visualizar as manifestações patológicas, quais as mais recorrentes e quais as possíveis causas. Com vista nos resultados do estudo das dez edificações abordadas no presente trabalho e de levantamento bibliográfico de trabalhos anteriores elaborados por (ANAPRE, 2019), (BALESTRINI; DALLAGNO; SARTORI, 2012), (CINTRA, 2013), (CRISTELLI, 2010), (FARIA, 2015), (LIBERATORE, 2015), (MARCONDES, 2008), (MONTARDO, 2006), (OLIVEIRA, 2000), (PORTELA, 2016), (RODRIGUES, 2006), (SILVA, 2013), (SOUZA, 2013), e por resoluções normativas (NBR 12655:2006), (NBR 7212:2012), (NBR, 15575: 2013), (NBR 7583: 1986), (NBR 6118: 2003), chega-se à abordagem de medidas que podem ser tomadas para que a execução e manutenção de pisos reduzam as incidências de falhas nos mesmos, quando efetuadas corretamente. 
Tabela 1 - Identificação e informações iniciais das edificações estudadas

\begin{tabular}{c|c|c|c|c}
\hline Designação & Local & Idade & Tipo de Tráfego & Ambiente de uso \\
\hline Edificação 1 & Curitiba-PR & 15 anos & Veículos e pedestres & Aberto \\
\hline Edificação 2 & $\begin{array}{c}\text { Balneário Camboriú- } \\
\text { SC }\end{array}$ & - & $\begin{array}{c}\text { Pessoas, veículos, } \\
\text { carrinhos de compras e } \\
\text { alguns maquinários }\end{array}$ & Estacionamento de um mercado \\
\hline Edificação 3 & Passo Fundo - RS & 10 anos & Veículos & Garagem de edificio residencial \\
\hline Edificação 4 & Passo Fundo - RS & 30 anos & Veículos & Garagem de edificio residencial \\
\hline Edificação 5 & $\begin{array}{c}\text { Balneário Camboriú- } \\
\text { SC }\end{array}$ & 20 anos & Veículos & Garagem de edificio residencial \\
\hline Edificação 6 & $\begin{array}{c}\text { Balneário Camboriú- } \\
\text { SC }\end{array}$ & - & Veículos & Garagem de edificio residencial \\
\hline Edificação 7 & $\begin{array}{c}\text { Balneário Camboriú- } \\
\text { SC }\end{array}$ & 5 anos & Veículos & Garagem de edificio residencial \\
\hline Edificação 8 & Itajaí-SC & 5 anos & Veículos & Garagem residencial \\
\hline Edificação 9 & Itajaí-SC & 14 anos & Veículos & Estacionamento residencial aberto \\
\hline Edificação 10 & Itajaí-SC & - & Veículos & Estacionamento rotativo \\
\hline
\end{tabular}

\section{RESULTADOS}

O processo de execução do piso foi utilizado como parâmetro de comparação para os pisos presentes nas edificações em questão, sendo expressa na Figura 1 a sequência de atividades realizadas.

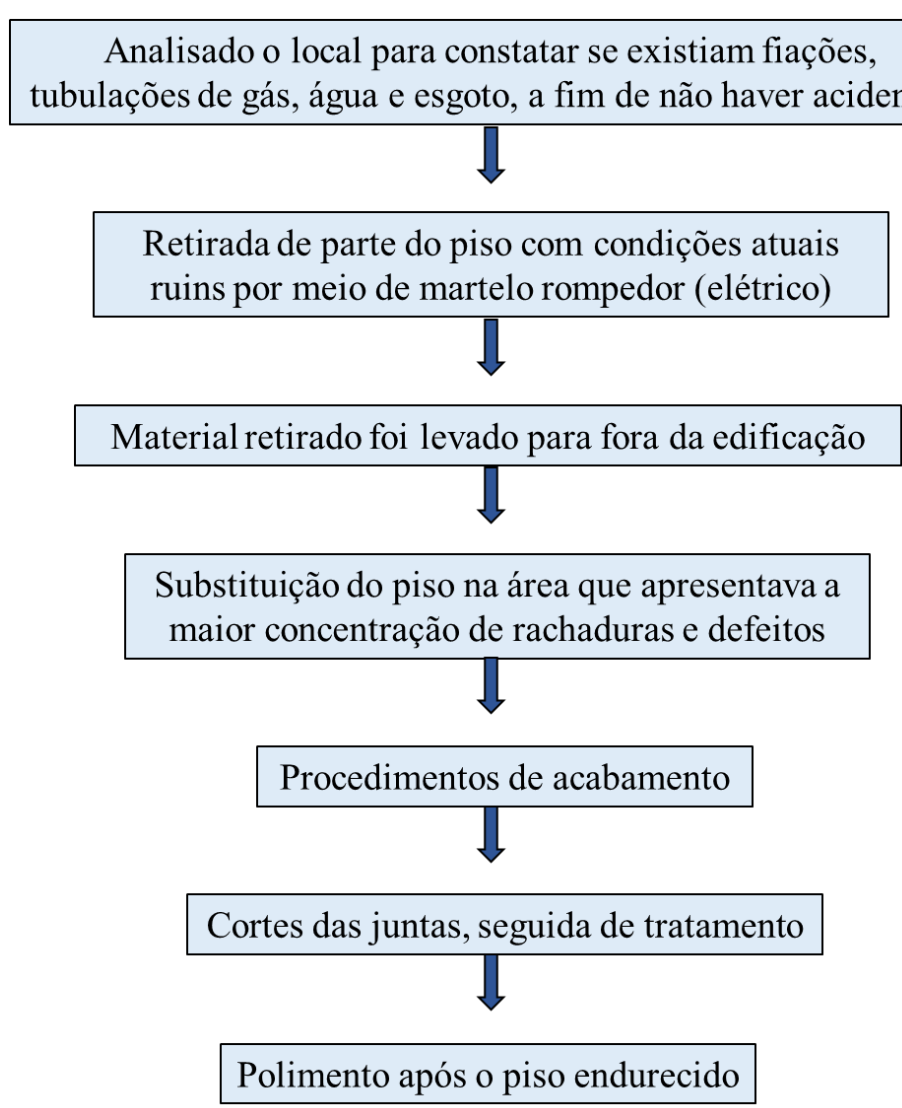

Figura 1: Fluxograma de atividades empregadas no processo de recuperação de piso

A área total do $2^{\circ}$ pavimento da Edificação 1 (Tabela 1) é de $468 \mathrm{~m}^{2}$, a área de piso de garagem é de $391 \mathrm{~m}^{2}$, foi realizada a substituição do piso de $238 \mathrm{~m}^{2}$, área que apresenta a maior concentração de rachaduras e defeitos (Figura 2 (a)). Sendo 
que o piso atual foi substituído por piso de concreto polido de $8 \mathrm{~cm}$ de espessura. A resistência característica à compressão ( $f_{c k}$ ) desse concreto é $30 \mathrm{MPa}$. O slump test utilizado de $10 \pm 2 \mathrm{~cm}$ e a relação a/c de 0,53 .

A armadura superior utilizada foi a tela soldada de fios de aço CA-60 do tipo Q92 (malhas quadradas) com diâmetro (longitudinal e transversal) de 4,2 $\mathrm{mm}$ e malhas de $(15 \times 15) \mathrm{cm}$, a mesma foi posicionada a $2,7 \mathrm{~cm}$ da face superior do piso (aproximadamente 1/3 da espessura do mesmo), com o auxílio de espaçadores apropriados, como pode ser observado na Figura 2 (b). Nesse piso foram utilizadas barras de transferência em todas as juntas, com diâmetro adotado de $10 \mathrm{~mm}$ e de aço liso com comprimento de $50 \mathrm{~cm}$, essas foram posicionadas na metade da espessura do piso e a metade dela foi pintada e engraxada. Após posicionadas as armaduras e espassadores, teve início a concretagem, seguida pelo nivelamento do piso e procedimentos de acabamento (Figura 2 (c)).

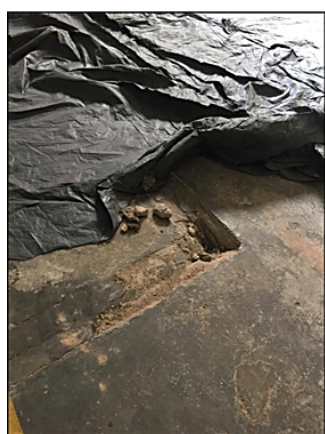

(a)

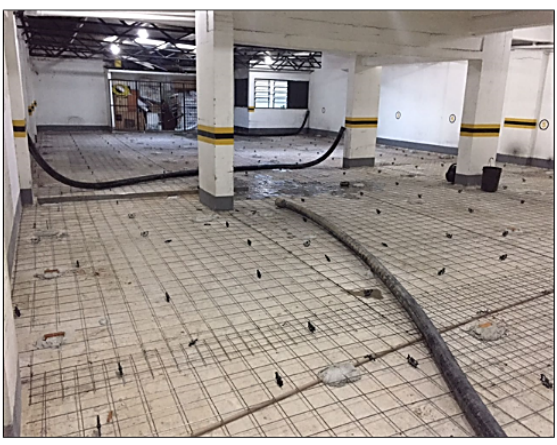

(b)

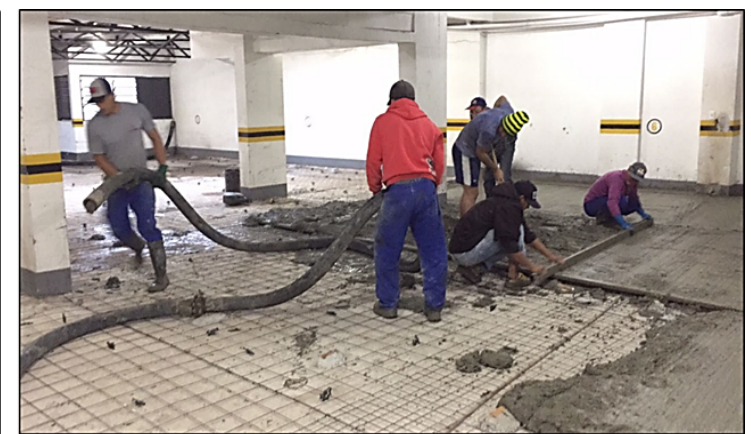

(c)

Figura 2: a) Piso de concreto antes da recuperação, b) serviço de recuperação com a armadura posicionada e c) concretagem do piso de concreto

Encerrados os procedimentos de acabamento, foram feitos os cortes das juntas, com $30 \mathrm{~mm}$ de profundidade e abertura de $6 \mathrm{~mm}$, formando ângulo de $90^{\circ}$ no encontro entre duas juntas, cujo tratamento foi feito com selante poliuretano (PU). Após o endurecimento superficial do piso, foi realizado o polimento, tornando o piso brilhante e bem acabado. Foi adotado para cura inicial do concreto um tempo mínimo de 10 dias. Esses dados serviram como efeito de comparação para as análises feitas no levantamento das incidências das manifestações patológicas em cada uma das edificações, a partir do qual teve os seguintes resultados de avaliação.

$\mathrm{Na}$ Edificação 1 foram encontradas fissuras contínuas causadas pela falta de execução de juntas de dilatação (Figura 3 (a)), juntamente com execução incorreta do processo de cura, o que ocasionou a quebra do concreto entre o ralo e o piso de concreto (Figura 3 (b)), podendo-se apontar a falha na fase de projeto. Houve também desplacamento do piso e camada de base exposta, possivelmente em decorrência da falta de aderência entre o concreto antigo e o novo, pois para a execução da camada nova, não houve a retirada da camada superficial antiga (Figura 3 (c)). Com destaque para o fato do piso já ter sofrido diversos reparos, feitos de maneiras incorretas, assim as manifestações patológicas foram sempre recorrentes, onde somente tinham falhas mais críticas, sem nenhum processo de cura adequado ou nivelamento (Figura 3 (d)).

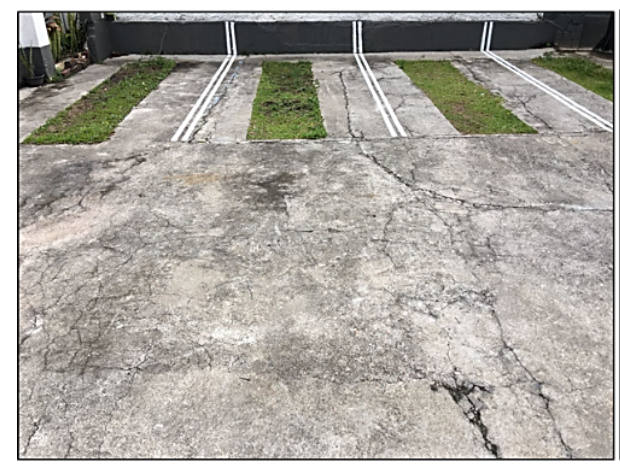

(a)

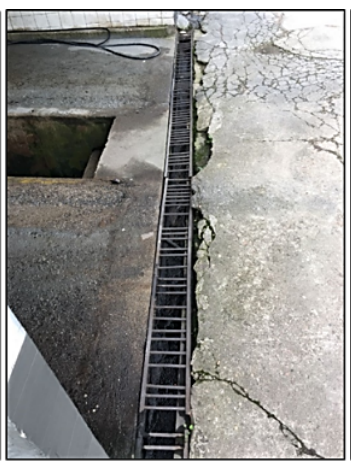

(b)

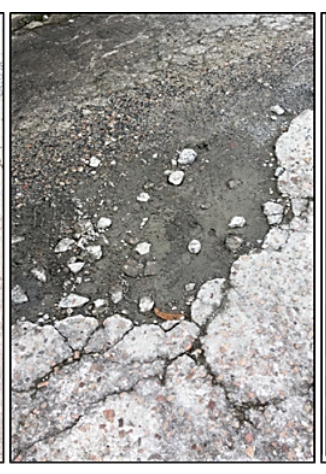

(c)

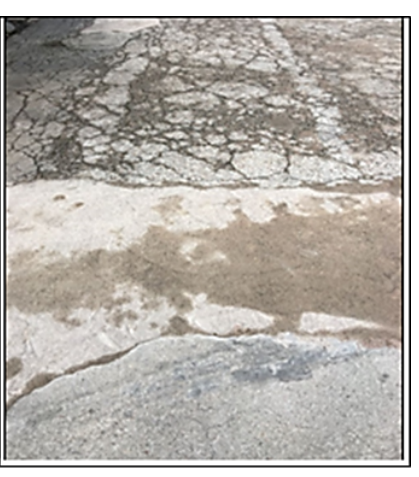

(d)

Figura 3: a) Piso de garagem da edificação 1, b) quebras do concreto junto ao ralo, c) desplacamento com exposição da base e d) região com reparo do piso 


\section{CBPAT 2020

Foi encontrado, na Edificação 2, o piso com acabamento de concreto polido e sugerindo que o concreto utilizado foi pobre em cimento ou o processo de vibração foi executado em excesso, pela presença de agregados graúdos visíveis na camada superficial do piso (Figura 4 (a)). Haviam placas quebradas na Edificação 3 ( Figura 4 (b)) e pulverulência com acúmulo de agregado graúdo na Edificação 4 (Figura 4 (c)). Na Edificação 5, o fenômeno de delaminação ocorre quando os processos de acabamento são executados antes do endurecimento superficial do concreto, selando o piso e impedindo a saída da água, enquanto que o desgaste por abrasão está ligado aos materiais constituintes do concreto e seu uso, por isso é provável que essa manifestação patológica ocorreu devido ao tráfego de pessoas ou automóveis (Figura 4 (d)).

O esborcinamento de juntas foi atribuído pela falta de tratamento das mesmas, uma vez que não foi possível visualizar nenhum material de preenchimento. Na Edificação 6, não foram encontradas muitas manifestações patológicas com maior presença de quebras nas juntas entre placas, (Figura 4 (e)) apesar de ter cinco pavimentos de garagem, o oposto ocorreu na Edificação 7, tendo inclusive derramamento de resto de concreto sobre o piso pronto, claro descaso com a execução do mesmo. As juntas de dilatação encontradas no piso, foram executadas de maneira incorreta, sem nenhum tipo de preenchimento ou preenchidas com material rígido e em número reduzido, além de não ter uniformidade na espessura do corte (Figura 4 (f)).

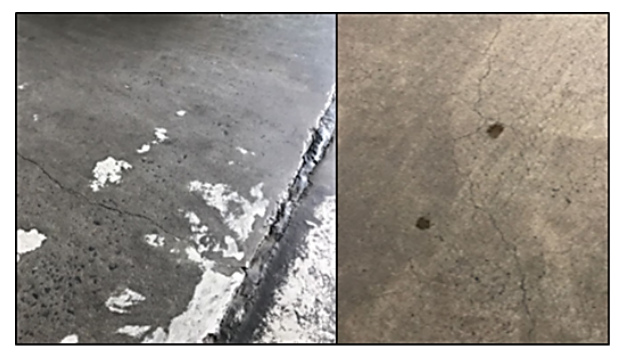

(a)

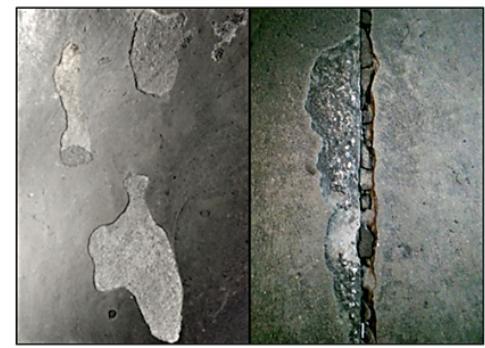

(d)

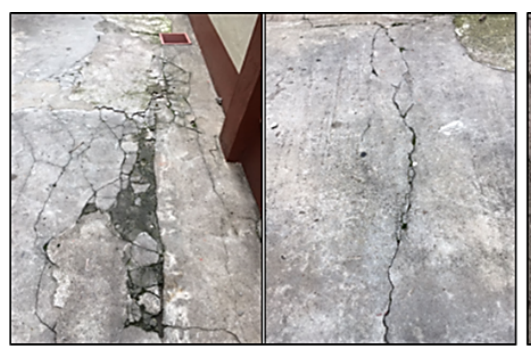

(b)

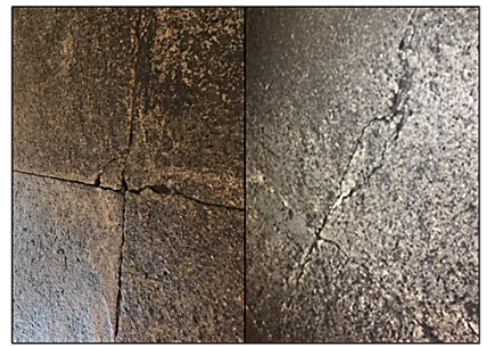

(e)

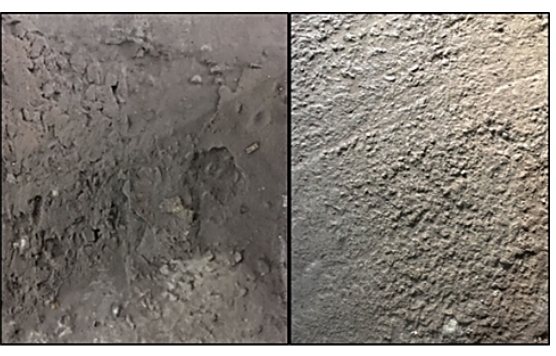

(c)

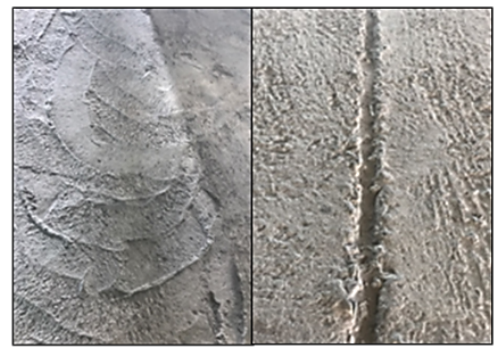

(f)

Figura 4: a) Fissuração e agregados visíveis, b) quebras na placa de concreto, c) material pulverulento e agregados expostos, d) delaminação e esborcinamento de juntas, e) quebra de juntas e f) acabamento e juntas mal executados

A Edificação 8 teve fissuração paralela às juntas e desgaste (Figura 5 (a)), tendo em vista que na Edificação 9 a camada de concreto superficial conta com espessura reduzida, grande parte já foi desplacada ocasionando ruptura e exposição da camada de base (Figura 5 (b)). Enquanto que na Edificação 10 haviam placas quebradas, fissuração e delaminação (Figura $5(\mathrm{c}))$.

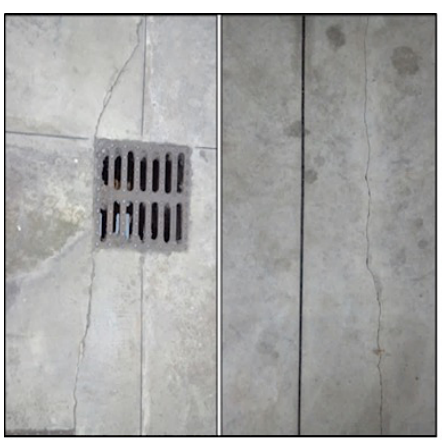

(a)

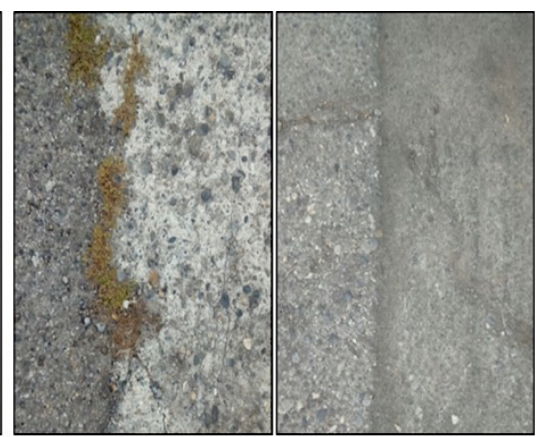

(b)

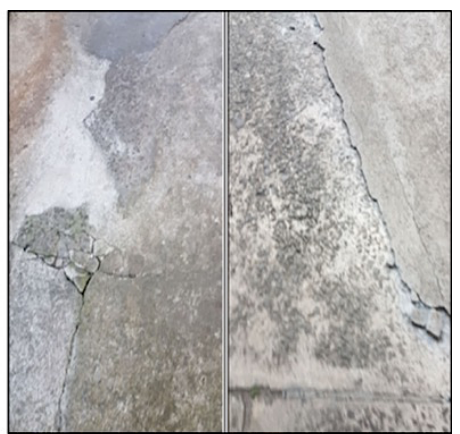

(c)

Figura 5: a) Fissuração e desgaste, b) camada de base exposta e falhas de acabamento, e c) quebras, fissuras e delaminação 
Foram reunidos os resultados de análise das dez edificações, dando enfoque às características visuais das manifestações patológicas e suas possíveis causas, apresentando-os na Tabela 2.

Tabela 2 - Resultados de análise de manifestações nas edificações bem como suas possíveis causas

\begin{tabular}{|c|c|c|c|}
\hline Edificação & Reparação Anterior & Análise Visual & $\begin{array}{c}\text { Possíveis Causas } \\
\end{array}$ \\
\hline $\begin{array}{c}\text { Edificação } \\
1\end{array}$ & Presente & $\begin{array}{l}\text { Agregados graúdos expostos; } \\
\text { Ausência de armaduras; } \\
\text { Camada de piso fina; } \\
\text { Destacamento de concreto; } \\
\text { Fissuras contínuas; } \\
\text { Fissuras de retração. }\end{array}$ & $\begin{array}{l}\text { Concreto pobre em cimento ou a falta } \\
\text { de aderência entre o concreto antigo e o } \\
\text { novo; } \\
\text { Delaminação; } \\
\text { Falta de resistência à abrasão; } \\
\text { Traço pobre. }\end{array}$ \\
\hline $\begin{array}{l}\text { Edificação } \\
2\end{array}$ & Ausente & $\begin{array}{l}\text { Agregados graúdos expostos; } \\
\text { Esborcinamento de juntas; } \\
\text { Falta de preenchimento de juntas; } \\
\text { Microfissuras de retração. }\end{array}$ & $\begin{array}{c}\text { Camadas inferiores com baixo suporte } \\
\text { e capacidade; } \\
\text { Falha de projeto; } \\
\text { Recalque diferencial; } \\
\text { Traço pobre. }\end{array}$ \\
\hline $\begin{array}{l}\text { Edificação } \\
3\end{array}$ & Presente & $\begin{array}{l}\text { Ausência de juntas de dilatação; } \\
\text { Desgaste e quebra da placa de } \\
\text { concreto; } \\
\text { Empenamento das placas; } \\
\text { Fissuras em grande número. }\end{array}$ & $\begin{array}{l}\text { Falha de projeto; } \\
\text { Mau uso do piso. }\end{array}$ \\
\hline $\begin{array}{l}\text { Edificação } \\
4\end{array}$ & Ausente & $\begin{array}{c}\text { Alguns pontos de disgregação; } \\
\text { Agregados graúdos expostos e se } \\
\text { desprendendo; } \\
\text { Agregados miúdos expostos; } \\
\text { Falta de procedimentos de } \\
\text { acabamento; } \\
\text { Fissuração; } \\
\text { Presença de pulverulência. }\end{array}$ & $\begin{array}{l}\text { Ausência de juntas de dilatação; } \\
\text { Falta ou excesso de adensamento; } \\
\text { Falta de argamassa no concreto; } \\
\text { Utilização do piso antes do concreto } \\
\text { estar endurecido; } \\
\text { Retração; } \\
\text { Traço pobre. }\end{array}$ \\
\hline $\begin{array}{l}\text { Edificação } \\
5\end{array}$ & Presente & $\begin{array}{c}\text { Descolamentos da camada } \\
\text { superficial; } \\
\text { Desgaste; } \\
\text { Esborcinamento de juntas. }\end{array}$ & $\begin{array}{l}\text { Cura ineficiente ou inexistente; } \\
\text { Delaminação; } \\
\text { Falta de tratamento das juntas; } \\
\text { Tráfego de pessoas ou automóveis. }\end{array}$ \\
\hline $\begin{array}{l}\text { Edificação } \\
6\end{array}$ & Presente & $\begin{array}{l}\text { Agregados graúdos expostos; } \\
\text { Aspereza do concreto; } \\
\text { Quebra das quinas no encontro } \\
\text { entre as placas. }\end{array}$ & Traço pobre. \\
\hline $\begin{array}{l}\text { Edificação } \\
7\end{array}$ & Ausente & $\begin{array}{l}\text { Agregados graúdos expostos; } \\
\text { Falta de acabamento e acabamento } \\
\text { mal feito do concreto; } \\
\text { Juntas de dilatação mal } \\
\text { executadas. }\end{array}$ & $\begin{array}{c}\text { Ausência dos procesos de vibração; } \\
\text { Falhas na execução; } \\
\text { Traço pobre. }\end{array}$ \\
\hline $\begin{array}{l}\text { Edificação } \\
8\end{array}$ & Ausente & $\begin{array}{l}\text { Fissuração em todo o piso; } \\
\text { Desgaste por abrasão; } \\
\text { Microfissuras de retração. }\end{array}$ & $\begin{array}{c}\text { Falta de material flexível no encontro } \\
\text { entre o ralo e o piso; } \\
\text { Número reduzido de juntas; } \\
\text { Retrações. }\end{array}$ \\
\hline $\begin{array}{l}\text { Edificação } \\
9\end{array}$ & Presente & $\begin{array}{c}\text { Agregados graúdos expostos; } \\
\text { Desplacamento; } \\
\text { Falta de juntas; } \\
\text { Falhas no acabamento. } \\
\end{array}$ & $\begin{array}{l}\text { Cura ineficiente; } \\
\text { Execução incorreta; } \\
\text { Traço pobre. }\end{array}$ \\
\hline $\begin{array}{l}\text { Edificação } \\
10\end{array}$ & Pobre & $\begin{array}{l}\text { Delaminação; } \\
\text { Fissuração; } \\
\text { Quebras. }\end{array}$ & Traço pobre. \\
\hline
\end{tabular}

A Figura 6 (a) mostra quais as manifestações patológicas mais incidentes nos pisos, com detaque para problemas de juntas em $100 \%$ das edificações visitadas. A segunda manifestação patológica mais encontrada foi a falta de argamassa nos 
pisos, devido ao mau proporcionamento do concreto ou à vibração em excesso. Em pisos geralmente são utilizados traços pobres (economia na obra), porém, um concreto com os agregados expostos na parte superior tem maiores chances de disgregação e desplacamentos.

Em $60 \%$ das edificações avaliadas, não foram encontradas juntas ou número era insuficiente, em $30 \%$ houve a falta de preenchimento e tratamento delas e em $10 \%$ ocorreu esborcinamento devido ao preenchimento incorreto ou não preenchimento das mesmas. As fissurações foram encontradas em $70 \%$ das edificações, esse dado pode indicar falha no processo de execução e/ou cura inadequada, mas também pode ser indício de que os materiais utilizados para compor o concreto não foram os adequados. As outras manifestações encontradas, mas em menor recorrência, indicam falha na escolha dos materiais e execução, estando clara a necessidade de aprofundamento de estudos na área de pisos. No caso da manifestação patológica exsudação, não foi apontada a sua aparição, pois ela ocorre em fase plástica. A Figura 6 (b) mostra as causas das manifestações patológicas de acordo com a proporção de manifestações patológicas evidenciadas.

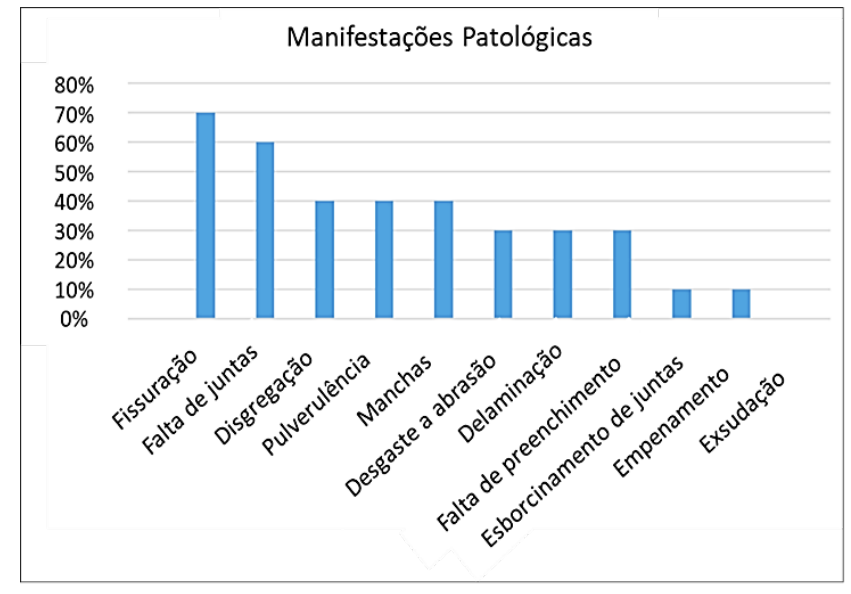

(a)

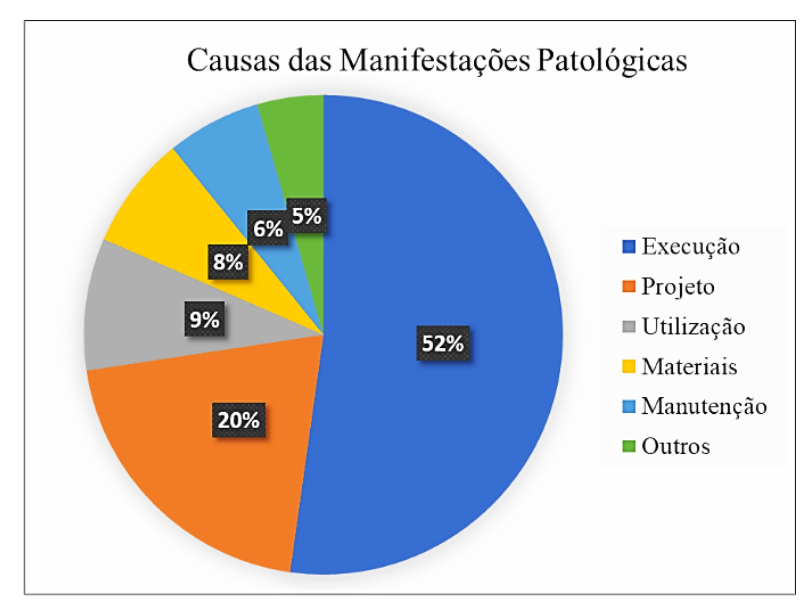

(b)

Figura 6: a) Incidências das manifestações patológicas e b) principais causas apontadas pelo levantamento fotográfico e visita à edificação

Grande parte das manifestações patológicas ocorre por ausência de uma correta execução e falta de atenção às propriedades dos agregados no preparo do projeto e falta de uma padronização de etapas e fatores constituintes, como juntas, no processo produtivo dos pisos, resultando em retrações, fissuras e traços deficientes. Esses fatores são indicadores de mão de obra despreparada ou processos executivos ausentes, além de falta de informações por parte dos usuários que fizeram uso do piso durante o processo de secagem, apontando ausência de sinalização adequada, e desinteresse em promover manutenção em edificações quando necessárias.

Após o levantamento bibliográfico acerca de execução, manutenção e manifestações patológicas em pisos de concreto, elaborados por (ANAPRE, 2019), (BALESTRINI; DALLAGNO; SARTORI, 2012), (CINTRA, 2013), (CRISTELLI, 2010), (FARIA, 2015), (LIBERATORE, 2015), (MARCONDES, 2008), (MONTARDO, 2006), (OLIVEIRA, 2000), (PORTELA, 2016), (RODRIGUES, 2006), (SILVA, 2013), (SOUZA, 2013), e por resoluções normativas (NBR 12655:2006), (NBR 7212:2012), (NBR, 15575: 2013), (NBR 7583: 1986), (NBR 6118: 2003), aliado aos resultados obtidos por estudo das dez edificações, passa-se a discutir sobre os métodos e ações tomadas para que sejam feitos pisos com reduzidas manifestações patológicas. Tratando-se tanto dos processos executivos, como também da constatação de problemas, manutenção e recuperação de pisos.

Primeiramente, há requisitos de desempenho que um piso deve atender como o fato de não apresentar ruínas ou falhas que colocam em risco a integridade do usuário, ter limitados os deslocamentos verticais e fissuras, apresentar coeficiente de atrito da superfície em que a circulação de usuários seja segura, possuir planeza com valores iguais ou inferiores a $3 \mathrm{~mm}$ com régua de $2 \mathrm{~m}$ em qualquer direção, ser estanque à umidade e resistente aos impactos de condições de serviço e cargas. Para base solo devem ser executadas sub-base, lona, placa de concreto e acabamento, enquanto que para uma base laje pode haver camada de isolamento térmico ou acústico, seguida de contrapiso e piso acabado.

O traço ou dosagem sugeridos para pisos são $1: 2,5: 3,5: 0,55$, para tráfego de veículos leves ou pessoas e $1: 4: 6$ : 0,55, traço de concreto magro, quando for receber outra camada de acabamento por cima. É recomendada a adoção dos 
tipos de cimento mais utilizados para pisos de concreto são Cimento Portland de Alta Resistência Inicial (CPV - ARI) para projetos com urgência de liberação para uso, Cimento Portland de Alto Forno (CP III) para melhor trabalhabilidade e ambientes nocivos, e Cimento Portland Pozolânico (CP IV) para concretagem de grandes volumes e meios agressivos. Contudo a outros tipos podem ser usados, desde que seja comprovada eficiência e não se altere as características desejadas.

A relação a/c pode variar se houver uso de aditivos, entretanto um possível valor é 0,55 , é preciso fazer a melhor escolha quanto aos tipos de agregados, aditivos e fibras, tendo por base suas propriedades, finalidade e melhor uso. Quanto às armaduras e telas soldadas, podem ser tanto estruturais, como estáticas, sendo que as telas soldadas devem ser posicionadas a 1/3 da camada superior de concreto com cobrimento de $5 \mathrm{~cm}$. Para a execução do piso de concreto, metade do comprimento das barras de transferância deve ser lubrificada pois elas são responsáveis por limitar as movimentações horizontais e é indicado o tratamento da camada superficial do piso por endurecimento de superfície por haver aumento da vida útil, melhoria em estética, manutenção e limpeza do piso, sendo feito por produtos à base de silicato, fluosilicato ou Diamond Hard.

As juntas mais empregadas em pisos de concreto são as juntas de retração, que reduzem a ocorrência de trincas e fissuras; juntas de construção, para encontro de concretos produzidos em momentos diferentes que é local propício de manifestações patológicas; juntas de encontro para situações em que o piso deve trabalhar independente de outros componentes da edificação; e juntas serradas com função de receber as maiores movimentações causadas por retração do concreto, sendo que seus cortes devem ter abertura de 3-6 mm e profundidade mínima de $1 / 3$ da espessura. O tratamento das juntas deve ter seus materiais determinados por projetista para se adequar a cada caso e pode ser executado por sistema de pré-moldados ou moldado no local, o primeiro é usado onde há tráfego intenso de veículos ou máquinas e por ter elevado custo é empregado em casos mais específicos.

Os tipos de pisos existentes são os pisos de concreto simples, com armadura distribuída, estruturalmente armados, reforçados com fibras e de concreto protendido. Em pisos de concreto simples, indicados em casos de pequenas aplicações de cargas, todo o carregamento é suportado pelo concreto, pois não há armaduras e caso haja barras de transferência elas terão o papel de transferir cargas entre placas. Na execução desses pisos deve haver menor relação água cimento para aumento de resistência e redução de fissuração, assim como correto procedimento de cura por conta de maior retração; as camadas devem ser espessas e rígidas; maior número de juntas; se houver uso de barras de transferência a espessura do piso deve ser $15-45 \mathrm{~cm}$ e pacas de $7 \mathrm{~m}$, caso contrário a espessura deve ficar entre 15 e $20 \mathrm{~cm}$ com placas de 4 a $5 \mathrm{~m}$.

Pisos com armadura distribuída possuem telas soldadas contínuas ou interruptas posicionadas a 1/3 da parte superior da placa, com no mínimo $5 \mathrm{~cm}$ de cobrimento para evitar agentes patológicos, sem necessidade de grande quantidade de juntas, sendo necessário o uso de barras de transferência tratadas e tela interruptas quando houver juntas serradas no controle de fissuração. Os pisos estruturalmente armados possuem armadura positiva para suportar os esforços de tração e barras de transferência.

Os pisos reforçados com fibras apresentam esse material para resistir principalmente a esforços de tração, controlando a ocorrência de fissuras, dispensando o uso de armaduras e barras de transferência nas juntas, além disso as fibras diminuem casos de esborcinamneto de quinas. Há facilidade na etapa de vibração durante a concretagem, contudo é preciso ter cuidado para evitar acúmulo das fibras e agregados. Em se tratando de pisos protendidos, há grande vantagem no fato de ser possível executar até $100 \mathrm{~m}$ sem a presença de juntas e diminuir as manifestações patológicas oriundas do mal funcionamento desses elementos, sendo comum em aeroportos.

Qunato aos métodos de execução dos pisos de concreto, a Tabela 3 traz as recomendações para cada processo com base nos estudos bibliográficos e no sequencial de execução de um piso abordado anteriormente. É recomendado que o corte de juntas seja feito com serras diamantas, com cortes perpendiculares ao eixo do piso, primeiramente no sentido longitudinal e depois transversal, pois é onde inicia a fissuração, após o processo é feita limpeza. A profundidade máxima do corte é de $12 \mathrm{~mm}$ e das juntas transversais é de $1 / 4$ da espessura da placa.

Os acabamentos podem ser de concreto polido, cujo procedimento dura cerca de 5-6 horas, ou camurçado que por ser acabamento áspero requer em torno de 3 horas, no vassourado há os mesmos processos de acabamento anteriores com o diferencial de a riscagem do concreto ser por meio de um vassourão. Argamassas autonivelantes também servem de acabamento para pisos, nesse processo o pavimento é liberado para uso após 8 horas para tráfego leve e 24 horas para tráfego intenso. A cura precisa ser feita de forma adequada para evitar problemas na superfície do piso, iniciando logo com os primeiros sinais de endurecimento do concreto, a cura complementar é realizada assim que ocorre o fim de pega e deve durar até que se tenha $75 \%$ da resistência final. Para cura úmida há duração de 7-14 dias conforme a exposição do 
concreto e relação a/c, em se tratando da cura química, não é recomendada quando o piso requerer camada de revestimento por evitar a ancoragem, já a cura térmica é mais frequente em pré-moldados.

Tabela 3 - Considerações quanto à execução de pisos de concreto

\begin{tabular}{|c|c|c|c|}
\hline \multicolumn{4}{|c|}{ Processo de Execução } \\
\hline iso & Base solo & Sub & ação da lona \\
\hline $\begin{array}{l}\text { - Limpeza da base; } \\
\text { - Nivelamento; } \\
\text { - Marcação dos níveis; } \\
\text { - } \text { Execução das taliscas; } \\
\text { - Preparo da camada de aderência, } \\
\text { usa-se aditivo polimérico e é } \\
\text { polvilhado cimento; } \\
\text { - Preenchimento com argamassa e } \\
\text { compactação; } \\
\text { - Retirada de excessos com régua } \\
\text { e uso de desempenadeira para } \\
\text { corrigir falhas; } \\
\text { - Acabamento superficial com } \\
\text { cimento polvilhado e alisamento. }\end{array}$ & 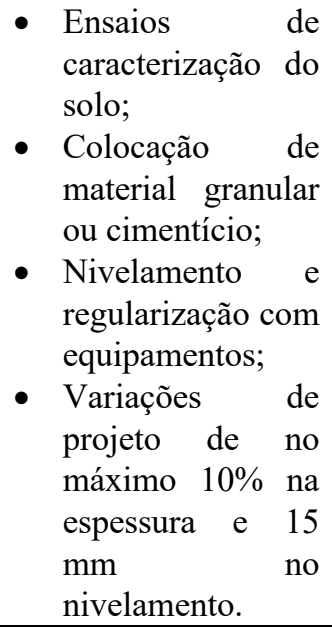 & 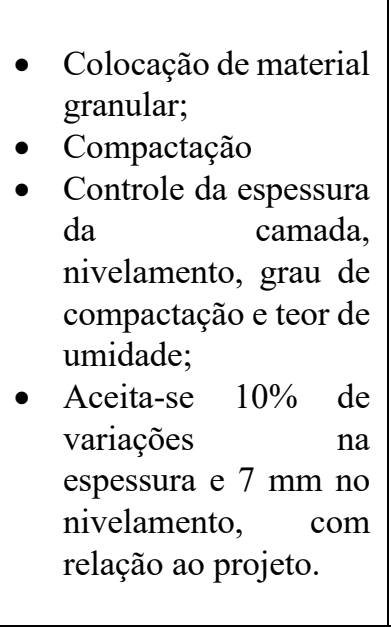 & $\begin{array}{l}\text { - Colocação de lona } \\
\text { entre o concreto e a } \\
\text { sub-base, } \\
\text { transpassada } 30 \mathrm{~cm} \\
\text { das emendas, para } \\
\text { evitar passagem de } \\
\text { umidade; } \\
\text { - Largura conforme as } \\
\text { faixas de } \\
\text { concretagem, estando } \\
\text { entre } 2-8 \mathrm{~m} \text { e } 2 \text { mm de } \\
\text { espessura. }\end{array}$ \\
\hline & \multicolumn{3}{|c|}{ Processos em conjunto com a concretagem } \\
\hline $\begin{array}{l}\text { - Formas posicionadas a altura } \\
\text { inferior ao piso para melhor } \\
\text { acabamento; } \\
\text { - Fixação por pontas de ferro ou } \\
\text { cunhas de madeira; } \\
\text { - Nivelamento e alinhamento } \\
\text { verificados após instalação; } \\
\text { - Armadura superior posicionada } \\
\text { e sustentada por barra de aço } \\
\text { soldada ou distanciadores } \\
\text { soldados afastados } 80-100 \text { cm, } \\
\text { no caso de carangueijos deve } \\
\text { haver grande quantidade; } \\
\text { - Armadura inferior posicionada } \\
\text { com distanciadores plásticos de } \\
\text { 4-5 por m }{ }^{2} \text {, respeitando o } \\
\text { cobrimento mínimo. }\end{array}$ & $\begin{array}{l}\text { - As característica } \\
\text { - } \quad \text { Preftruturas; } \\
\text { minutos para os c } \\
\text { - Concreto descarr } \\
\text { também em } 30 \mathrm{~m} \\
\text { - Verificação das c } \\
\text { - Controle dos insu } \\
\text { - Cuidados com } \\
\text { - propriedades; } \\
\text { - } \text { Primeiramente é } \\
\text { - } \text { após o lançãamen é o m } \\
\text { Acabamento pod } \\
\text { abrasão, com du } \\
\text { - } \text { alisamento mecâr } \\
\text { Corte das juntas }\end{array}$ & $\begin{array}{l}\text { enes, com no máximo } \\
\text { ões climáticas e do sol } \\
\text { das cargas aplicadas } \\
\text { çamento do concret } \\
\text { tado um pano longo e } \\
\text { de adensamento mai }\end{array}$ & $\begin{array}{l}\text { diferentes do usado em } \\
\text { slump e intervalo de } 10 \\
\text { inutos para chegada; } \\
\text { çamento e adensamento } \\
\text { laje; } \\
\text { te e após o processo; } \\
\text { ra evitar alterações de } \\
\text { is são cortadas as placas; } \\
\text { do e deve ter início logo } \\
\text { aumentar a resistência à } \\
\text { ga. Corte, desempeno e } \\
\text { to que pode ser de } 6-12 \\
\text { Caso a profundidade das } \\
\text { ode haver fissuras por }\end{array}$ \\
\hline
\end{tabular}

Finalizados os processos executivos de pisos de concreto, é importante abordar as manifestações patológicas com a finalidade de diagnosticar as possíveis causas e apontar reparos. Conforme constatado nas edificações do presente trabalho, as manifestações patológicas podem ser decorrentes de falta de projeto, execução inadequada, desgaste, mau uso, alto índice de agressividade do ambiente, falta de normatização, controle tecnológico e qualidade por reduções de custo, além de manutenção imprópria ou ausência da mesma. A Tabela 4 traz as principais considerações que devem ser feitas na constatação de manifestações patológicas, bem como os danos gerados e medidas para prevenção e tratamento. 
Tabela 4: Processo de identificação de manifestações patológicas, tal como danos causados e metódos de controle

\begin{tabular}{|c|c|c|}
\hline Designação & Observação & Danos consequentes e controle \\
\hline Exsudação & $\begin{array}{l}\text { Água do concreto ascendente na } \\
\text { superfície. }\end{array}$ & $\begin{array}{l}\text { Gera vazios na placa de concreto, reduzindo sua } \\
\text { resistência. Deve ter aumento do teor de finos na } \\
\text { mistura e uso de de aditivos. }\end{array}$ \\
\hline Fissuração & $\begin{array}{l}\text { Aberturas pequenas feitas } \\
\text { longitudinalmente. Em pisos mais } \\
\text { espessos a fissura pode acompanhar a } \\
\text { direção da armadura, indicando que a } \\
\text { mesma está próxima da superfície. } \\
\text { Ambientes agressivos e recalques } \\
\text { podem gerar fissuras paralelas ou } \\
\text { perpendiculares às juntas. }\end{array}$ & $\begin{array}{l}\text { Causa redução de resistência, pode expor armaduras. } \\
\text { Recomenda-se cura adequada, redução de água do } \\
\text { traço para diminuir a retração. Cuidado na fase do } \\
\text { concreto plástico, exposição solar e ao vento. Uso de } \\
\text { telas soldadas. }\end{array}$ \\
\hline Microfissuração & $\begin{array}{l}\text { Fissuras de pequena profundidade com } \\
\text { abertura reduzida. }\end{array}$ & $\begin{array}{l}\text { Há ocorrência de fissuras maiores, redução da } \\
\text { resistência. } \\
\text { Os mesmos processos de controle para fissuração } \\
\text { podem ser adotados, além de atenção para o pó de } \\
\text { cimento ao induzir secagem e alto teor de finos na } \\
\text { mistura. }\end{array}$ \\
\hline Esborcinamento & $\begin{array}{l}\text { Quebras das juntas, ausência de barras } \\
\text { de transferência, perda do selante, sinais } \\
\text { de impacto por veículos ou máquinas. }\end{array}$ & $\begin{array}{l}\text { Falta de resistência da junta em decorrência de } \\
\text { esborciamento. O controle é por lábios poliméricos ou } \\
\text { revestidos com resina epóxi ou poliuretano. Quando o } \\
\text { tratamento é difinitivo é usado material mais resistente. }\end{array}$ \\
\hline $\begin{array}{l}\text { Desgaste por } \\
\text { abrasão }\end{array}$ & $\begin{array}{l}\text { Tráfego intenso de pessoas ou veículos, } \\
\text { superfície com alteração do seu aspecto } \\
\text { visual inicial, aspecto de fosco. }\end{array}$ & $\begin{array}{l}\text { Pode causar destacamento do concreto. Cuidado com } \\
\text { misturas de alta relação a/c, execução de acabamento } \\
\text { com possibilidade de polimento, escolha de materiais } \\
\text { mais resistentes à abrasão. Evitar excesso de ar } \\
\text { incorporado no concreto, efetuar cura correta. Uso de } \\
\text { endurecedores cimentícios ou químicos em concretos } \\
\text { novos, tal como argamassas de elevada resistência. }\end{array}$ \\
\hline Delaminação & $\begin{array}{c}\text { Soltura ou destacamento da camada } \\
\text { superficial do pavimento, comumente } \\
\text { de espessura } 4 \mathrm{~mm} \text {. Camada de } \\
\text { revestimento executada antes que as } \\
\text { anteriores tenham finalizado o estado } \\
\text { plástico. }\end{array}$ & $\begin{array}{l}\text { Está relacionada à exsudação e afeta grandemente a } \\
\text { durabilidade do pavimento. Controlar a umidade do } \\
\text { substrato e dosagem do concreto, como também a } \\
\text { relação a/c. Para correção são usadas argamassas } \\
\text { poliméricas, quando a delaminação for de } 4-6 \mathrm{~mm} \text { e } \\
\text { cimentícias quando for de } 8 \mathrm{~mm} \text { ou mais. }\end{array}$ \\
\hline Empenan & $\begin{array}{l}\text { Mal nivelamento, deixando os cantos } \\
\text { das placas com espessuras diferentes. } \\
\text { Presença de retração diferencial. }\end{array}$ & $\begin{array}{l}\text { Resulta em quebra de placas, danos nas juntas. Efetuar } \\
\text { o nivelamento adequadamente, ter cuidado para efeitos } \\
\text { de retração. }\end{array}$ \\
\hline Pulverulência & $\begin{array}{l}\text { Material fino que se deposita na } \\
\text { superfície, ascensão dos materiais finos } \\
\text { com o concreto ainda em estado } \\
\text { plástico. }\end{array}$ & $\begin{array}{l}\text { Ocorre maior desgaste por atrito das partículas soltas } \\
\text { durante o tráfego de pessoas e veículos. Melhorar a } \\
\text { resistência à abrasão, cuidados com cura, alto teor de } \\
\text { cimento ou água. Para reparação os materiais soltos } \\
\text { precisam ser removidos e feito um recorte na camada } \\
\text { frágil ou aplicado endurecedor de superfície. }\end{array}$ \\
\hline Disgregação & $\begin{array}{l}\text { Deterioração ou descolamento de pisos, } \\
\text { geralmente em regiões próximas as } \\
\text { juntas e quinas. }\end{array}$ & $\begin{array}{l}\text { Os danos são exposição de camadas, propiciando mais } \\
\text { problemas. Evitar expansão de armaduras devido a sua } \\
\text { corrosão, juntas mal executadas, deficiência na } \\
\text { quantidade de armaduras, falta de camada de } \\
\text { aderência, cura ineficiente. }\end{array}$ \\
\hline Manchas & $\begin{array}{l}\text { Agregados graúdos expostos, ar } \\
\text { aprisionado por cura incadequada. }\end{array}$ & $\begin{array}{l}\text { Afeta a estética do piso. É recomendada a vibração de } \\
\text { forma correta e cura, usar quantidade adequada de } \\
\text { argamassa. }\end{array}$ \\
\hline
\end{tabular}




\section{CONCLUSÕES}

A análise e o estudo de processos de planejamento, execução e manutenção de pisos nas edificações empregadas foram de significativa importância para ressaltar as afirmações e recomendações para o preparo de pisos encontrados na literatura, mesmo sendo um assunto pouco abordado. Além de possibilitar a criação de um cenário de incidências patológicas aliadas as suas causas, dando espaço para o projetista aperfeiçoar os processos produtivos, dando-se enfoque também na etapa de execução, visto que essa se demonstrou como a principal causa de manifestações patológicas.A partir dessa pesquisa, foi possível fazer uma análise mais crítica das manifestações patológicas nos pisos, onde a disposição de agregados na superfície do piso, manifestação mais encontrada, ocorre diretamente por falha na execução do adensamento ou falha de projeto, quando se tem traços muito pobres em argamassa. Os problemas relacionados às juntas também ocorreram em grande proporção, confirmando a falha na fase de execução e projeto, esses resultados mostram que os profissionais da área ou não estejam devidamente qualificados ou não dão a devida importância à dosagem dos concretos destinados a pisos.

Outro fator agravante das manifestações patológicas é a falta ou realização incorreta de manutenções nos pisos, seja pela falta de instrução ou pela busca de custos reduzidos, em 30\% das edificações visitadas houve reparos com argamassa apenas onde se encontrou as manifestações patológicas, o famoso termo "tapa buraco", sem a retirada do piso deficiente e sem a devida aderência entre os concretos. Haja visto que os pisos ainda são tratados com menos importância que os outros elementos de concreto constituintes da edificação, justificado pela falta de bibliografias na área de pisos, assim agravam as falhas de execução e dimensionamento e acarretam pisos de baixa qualidade.

A responsabilidade de "normatizar" a utilização, pelo fabricante do produto, por vezes, se mostra necessária em virtude de tal escassez bibliográfica que acompanhe as inovações, tal como ocorre com o concreto seja para aumento de resistência mecânica, diminuição da retração ou aumento do tempo de pega, todos têm como função facilitar o lançamento e ampliar a utilização do concreto. Assim, a conscientização da manutenção periódica pode ser um grande passo para a obtenção de pisos com maior durabilidade e trabalhando com todo o seu desempenho. Essas informações provam a importância do manual que foi proposto nesse trabalho, pois o mesmo tem a pretensão de auxiliar a execução e atentar para informações importantes que devem ser verificados na etapa de projeto e execução, verifica-se a importância do estudo detalhado de cada caso, de execução e também de reparação do pavimento, para a redução de custos.

\section{REFERÊNCIAS}

ASSOCIAÇÃO BRASILEIRA DE NORMAS TÉCNICAS. NBR 7583: Execução de pavimento de concreto simples por meio mecânico. Rio de Janeiro, 1986. Disponível em: <http://docslide.com.br/documents/nbr-7583-execucao-depavimentos-de-concreto-simples-por-meio-mecanico.html>. Acesso em: 03 maio 2017.

NBR 6118: Projeto de estruturas de concreto - Procedimentos. Rio de Janeiro: Abnt, 2014.

NBR 7212: Execução de concreto dosado em central. Rio de Janeiro: Abnt, 2012.

. NBR 15575: Edificações habitacionais — Desempenho. Rio de Janeiro: Abnt, 2013. 63 p.

. NBR 126555: Concreto de cimento portland - Preparo, controle e recebimento - Procedimento. Rio de Janeiro: Abnt, 2006. 22 p.

Associação Nacional de Pisos e Revestimentos de Alto Desempenho, 11. 2009, São Paulo: 2009. Disponível em: $<$ http://site.anapre.org.br/>. Acesso em: 02 abr. 2017.

Balestrini, Alex; DAllagnO, Ana Lidia; SARTORI, Jeniffer L.. Pisos de Concreto Armado. 2012. Disponível em: <http://trabalhocc2-grupo13.blogspot.com.br/2012/04/5-execucao_28.html>. Acesso em: 01 mar. 2017.

CAMARGO, Maria de Fátima Santos. Pisos à base de cimento: caracterização, execução e patologias. 2010. $124 \mathrm{f}$. Monografia (Especialização em Engenharia Civil) - Curso de Engenharia Civil, Universidade Federal de Minas Gerais, Belo Horizonte, 2010.

CINTRA, Danielli C. B.; FONSECA, Eduardo L.; TRISTÃO, Fernando A.; VIEIRA, Geilma L. 2013. Estudos de procedimentos de adensamento do concreto por vibradores de imersão em obras na Grande Vitório - ES. Anais 
do $55^{\circ}$ Congresso Brasileiro do Concreto CBC2013. IBRACON, 2013. Disponível em: $<$ https://lemacufes.files.wordpress.com/2012/03/estudo-de-procedimentos-de-adensamento-do-concreto-por-vibradoresde-imersc3a3o-em-obras-na-grande-vitc3b3ria-es.pdf>. Acesso em: 05 out. 2017.

CRISTELLI, Rafael. Pavimentos Industriais de Concreto - Análise do Sistema Construtivo. 2010. 145 f. (Monografia - Curso de Engenharia Civil) - Universidade Federal de Minas Gerais, Belo Horizonte, 2010.

FARIA, Breno Macedo; RODRIGUES, Públio P. F.; SILVA, João B. R. Pavimentos Industriais de Concreto Armado. São Paulo: IBTS, 2015. Disponível em: <http://www.ibts.org.br/pdfs/manual_completo_final_grafica.pdf>. Acesso em: 11 out. 2017.

LIBERATORE, Hailton. Gestão de Projetos. São Paulo: Associação Nacional de Pisos e Revestimentos de Alto Desempenho, 2015. 29 slides, color. Disponível el $<$ http://anapre.org.br/pdfs/concrete2016/Palestra1_APRESENTACAO_LIBERCON.pdf>. Acesso em: 22 março 2017.

MARCONDES, Carlos Gustavo. Juntas em piso de concreto. São Paulo, 2008. 2 p. Disponível em: $<$ http://www.cimentoitambe.com.br/juntas-em-piso-de-concreto/>. Acesso em: 25 maio 2017.

MELLO, Antonio Vicente de Almeida et al. Estudo do conforto humano em pisos mistos (aço-concreto). Rem: Rev. Esc. Minas, Ouro Preto, v. 60, n. 2, p. 409-418, junho $2007 . \quad$ Disponível em: $<$ http://www.scielo.br/scielo.php?script=sci_arttext\&pid=S037044672007000200023\&lng=en\&nrm=iso $>$. Acesso em: 01 set. 2019.

MEZA DE LUNA, Alejandro et al. Experimental mechanical characterization of steel and polypropylene fiber reinforced concrete. Rev. Téc. Ing. Univ. Zulia. Maracaibo, v. 37, n. 2, p. 106-115, agosto 2014. Disponível em: $<$ http://ve.scielo.org/scielo.php?pid=S0254-07702014000200002\&script=sci_abstract\&tlng=en >. Acesso em: 01 set. 2019.

MÜLLER, Leonardo Besen. Manifestações patológicas em pisos de concreto: avaliação em garagens de edifícios residenciais da Grande Florianópolis. 2014. 109 f. TCC (Graduação) - Curso de Engenharia Civil, Departamento de Engenharia Civil, Universidade Federal de Santa Catarina, Florianópolis, 2014. Disponível em: $<$ https://repositorio.ufsc.br/xmlui/handle/123456789/127339>. Acesso em: 01 set. 2019.

NEVILLE, A. M. Propriedades do concreto. 5. ed. Porto Alegre: Bookman, 2016.

OLIVEIRA, Patrícia Lima. Projeto Estrutural de Pavimentos Rodoviários e de Pisos Industriais de Concreto, 2000. 246 f. Dissertação (Mestrado em Engenharia de Estruturas) - Universidade de São Paulo, São Carlos, 2000.

PORTELA, M. F. A.; SOBRINHO, C. W. P. Patologias em piso de concreto armado polido: um estudo de caso. Revista de Engenharia e Pesquisa Aplicada, v. 3, n. 1, 2016.

RODRIGUES, Públio P. F. Pavimentos Industriais de Concreto Armado: Projetos e Critérios Executivos. Instituto Brasileiro de Tela Soldada, IBTS, São Paulo, 2006.

RODRIGUES, P. P. F; MONTARDO. J. P. A influência da Adição de Fibras de Polipropileno nas Propriedades dos Concretos para Pisos e Pavimentos. In: Instituto Brasileiro do Concreto, 44, 2002, Belo Horizonte: IBRACON. Disponível em: https:/www.impercia.com.br/tecnologias/BOLETINS\%20TECNICOS/ ADITIVOS/ARTIGOS\%20TECNICOS $\% 20$ NEO $\% 20$ FIBRAS/A $\% 20$ In fluencia\%20da\%20Adicao\%20de\%20Fibras\%20de\%20Polipropileno\% 20nas\%20Propri.pdf. Acesso em: 17 set. 2017

SILVA, Guilherme Diehl Dutra. 2013. Juntas e seus tratamento em pisos industriais de concreto: análise da concepção do projeto, da execução e do tratamento das juntas em obras. 90 p. TCC (Graduação em Engenharia Civil) - Universidade Federal do Rio Grande do Sul., Porto Alegre, 2013.

SOUZA, Natália Cerqueira de. Análise de desempenho do contrapiso autonivelante em relação ao sistema tradicional. 2013. 119 f. Tese (Doutorado) - Curso de Engenharia Civil, Universidade Federal de Minas Gerais, Belo Horizonte, 2013. 